\title{
Novel Affordable, Reliable and Efficient Technologies to Help Addressing the Water-Energy-Food Nexus
}

\author{
Francesco Meneguzzo ${ }^{1,2}$ Federica Zabini $^{1}$, Lorenzo Albanese ${ }^{1}$ and Alfonso Crisci ${ }^{1}$
}

\begin{abstract}
Improving the food system sustainability and security is becoming an urgent global challenge. In this regard, one of the most effective routes is the shift of the human diet toward healthier and more sustainable consumption, involving in particular the prevalence of plant-based raw food materials. Controlled hydrodynamic cavitation (HC) technologies could help considerably in this transition. $\mathrm{HC}$ techniques are gaining increased scientific interest, and are quickly spreading across a wide range of technical fields, recently showing surprising performances with biological raw materials related to the food, agricultural and forestry sectors and resources. HC processes enjoy recognized advantages in the acceleration of the processing steps of plant-based food, the extraction of valuable bioactive compounds, the reduction and the valorization of waste streams, as well as the superior efficiency in resource use, energy consumption, process yield, and exergy balance than competing processes. Thus, HC is very promising candidate to help addressing the water-energy-food nexus, and, ultimately, sustainability. Findings obtained from direct experimental trials and recent literature concerning the applications of $\mathrm{HC}$ to food processing, provide a strong basis for novel investigation aimed at standardization, starting from the identification of the most suitable devices and the optimal processing parameters, eventually oriented to further spreading of HC applications.
\end{abstract}

\section{Introduction}

Food production accounts for a large share of the anthropogenic environmental impacts. Almost half of the ice-free land area of the Earth is used as cropland or pastureland, with the global agriculture and food production systems releasing more than $25 \%$ of all greenhouse gases (GHGs) (Tilman \& Clark, 2014), as well as being responsible for about one third of the soil degradation, and the main driver of losses of biodiversity (Bajželj et al., 2014).

The food production system is the largest user of freshwater and a key driver in pollution of aquatic and terrestrial ecosystems, due to agrochemicals and excessive use of nitrogen and phosphorus (Springmann et al., 2018). At the European level, the food sector is still one of the most water and energy demanding sectors (Rohmer, Gerdessen, \& Claassen, 2019).

In a recent study, it was estimated that, worldwide, 5.2 billion ton of carbon dioxide were emitted in 2010 by the food system (Springmann et al., 2018). As well, it occupied 12.6 million $\mathrm{km}^{2}$ of cropland, used $1,810 \mathrm{~km}^{3}$ of freshwater resources from surface and groundwater (bluewater), and spread $104 \mathrm{Tg}$ of nitrogen, and $18 \mathrm{Tg}$ of phosphorus in the form of fertilizers.

In the same study, the food production and consumption were projected to change between 2010 and 2050 because of the expected socioeconomic dynamics, such as the global population growth by about a third, and a tripling of the global income. As a result, the environmental pressure of the food system was predicted increasing by 50-

${ }^{1}$ HCT-agrifood Lab, Institute of Bioeconomy, National Research Council, 10 via Madonna del Piano, I50019, Sesto Fiorentino (FI), Italy

${ }^{2}$ Corresponding Author 
$92 \%$ for each indicator, in the absence of technological change and other mitigation measures, with GHG emissions growing by an average of $87 \%$, cropland use by $67 \%$, and bluewater use by 65\% (Springmann et al., 2018).

The urgency for securing food supply chains was also pointed out by several authors. It was based on rising population and income in emerging countries, leading to predict a doubling of food demand from 2000 to 2050, as well as on the impending shortage of both the needed energy inputs and the availability of further agriculturally usable land (Motesharrei et al., 2017; Taylor \& Tainter, 2016).

The sustainability of food production and supply chains is driven by energy efficiency, functionality, and waste reduction, as well as healthy diets are generally more sustainable. Indeed, it was estimated that the economic benefits of a shift to plant-based diets, due to reduced health care costs, would surpass the value of the environmental benefits, overall benefits totaling up to $13 \%$ of global gross domestic product in 2050 (Springmann, Godfray, Rayner, \& Scarborough, 2016).

On the environmental side, as pointed out by a recent study, the reason underlying the benefits brought by a shift to plant-based diets lies in the very limited conversion rate, around $15 \%$, of proteins derived from vegetable raw materials, used to feed livestock, which become eventually available to human consumption (Di Paola, Rulli, \& Santini, 2017). Therefore, the food production model based on animal-based proteins is much more expensive in terms of land area (2.4 to 33 times), and GHG emissions (2.4 to 240 times).

New or emerging technologies, aiming to improve or even replace existing ones in specific segments of the food production chain, should comply with the need for higher water and energy efficiency standards, as well as help to facilitate the transition to plantbased food. Among such technologies, those based on controlled hydrodynamic cavitation (HC) stand out for their relative cheapness and straightforward scalability, as well as the capability to enhance the extraction of bioactive compounds from plant materials, as extensively documented in a recent review for the fields of vegetable beverages and the wider food production and supply chain (Albanese \& Meneguzzo, 2019a).

$\mathrm{HC}$ is defined as the phenomenon of generation, growth and collapse of microbubbles due to pressure variations in a liquid flow, triggered and sustained by several different methods. The most practical and scalable methods foresee pumping the flow through one of more constrictions of suitable geometry, such as Venturi tubes and orifice plates, in comparison to which, devices based on rotating parts are much more expensive, and impose higher operating and maintenance costs (Sarvothaman, Simpson, \& Ranade, 2018).

The increase in kinetic energy at the constriction occurs at the expense of pressure, leading to microbubbles and nanobubbles generation, which subsequently collapse under pressure recovery downstream of the constriction (Gogate \& Pandit, 2001). The violent collapses of the cavitation bubbles result in the generation of localized hot spots endowed with extremely high-energy density (Pawar, Mahulkar, Pandit, Roy, \& Moholkar, 2017; Yasui, Tuziuti, Sivakumar, \& Iida, 2004), highly reactive free radicals and turbulence, which can result in the intensification of various physical/chemical phenomena. 
Recently, cavitation-based technologies got remarkable attention as efficient and affordable routes to the intensification of different physical and chemical processing applications, from wastewater remediation (Ciriminna, Albanese, Meneguzzo, \& Pagliaro, 2017; Dindar, 2016; Doltade et al., 2019), to preparation of nanoemulsions, biodiesel synthesis, water disinfection, and nanoparticle synthesis (Carpenter, Badve, et al., 2017), and many others. As well, in the recent past, cavitation gained a great reputation as a greener extraction method, and for its usefulness in the intensification of food and pharmaceuticals processes (Carpenter, Badve, et al., 2017; Panda \& Manickam, 2019a), mainly due to its capability to remove or degrade toxic solvents, reduce process time and energy consumption, and achieve higher extraction yield.

This review discusses the current state of $\mathrm{HC}$ applications to the food production chain, whose potential for large-scale, advantageous implementation has been largely recognized as not only feasible, but also relatively fast and straightforward. However, their full exploitation at the market level has been so far hindered by a persisting lack of standardization (Sarvothaman et al., 2018).

\section{Fundamentals of Controlled Hydrodynamic Cavitation}

This short presentation of fundamentals of HC processes is limited to nonmoving setups, such as Venturi tubes and orifice plates, i.e., the most practical and convenient ones, as mentioned in Section 1. Fig. 1(A) represents a circular-shaped Venturi tube with a convergence section, a nozzle, and a divergence section, whose respective geometries, in particular convergence and divergence angles, are dictated by a fairly long history of experiments, theory, and numerical modeling (Albanese, Ciriminna, Meneguzzo, \& Pagliaro, 2015). Fig. 1(B) represents a slit Venturi, generally endowed with higher performances in comparison with the circular setup (Carpenter, Badve, et al., 2017).

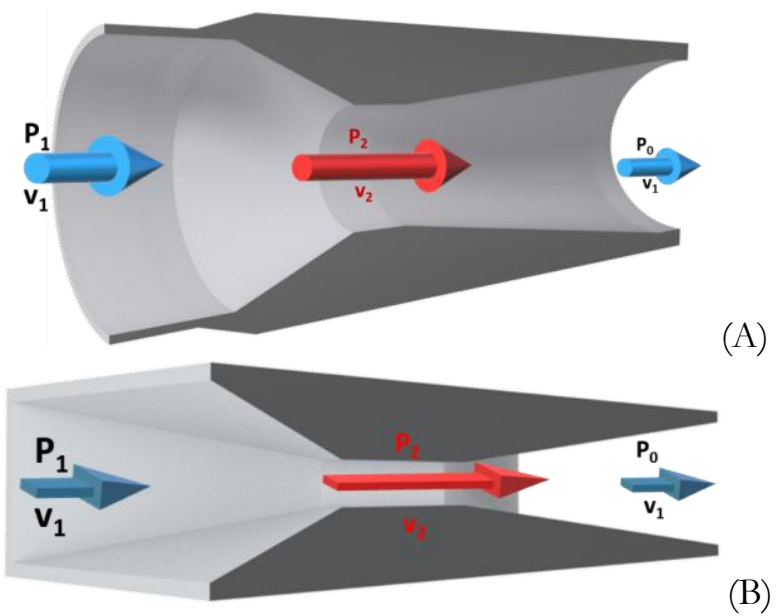

(B)

Figure 1. Schematic representations of $H C$ reactor in the form of a circular $(A)$ and slit (B) Venturi tube. $P_{1}, P_{2}$, and $P_{0}$, are the upstream bulk pressure, the pressure at the nozzle, and the downstream bulk pressure, respectively, whereas $v_{1}$ represents the fluid speed, upstream and downstream of the HC reactor, and $v_{2}$ represents the fluid speed at the nozzle of the HC reactor. 
The liquid acceleration, and the respective pressure drop, are regulated by the Bernoulli's equation (Pawar et al., 2017), i.e., the conservation of the mechanical energy for a moving fluid, represented in Eq. (1):

$$
P_{1}+\frac{1}{2} \rho v_{1}^{2}+\rho g h_{1}=P_{2}+\frac{1}{2} \rho v_{2}^{2}+\rho g h_{2}
$$

where $P_{1}$ and $P_{2}\left(\mathrm{Nm}^{-2}\right)$ are the upstream bulk pressure, and the pressure at the nozzle, respectively, $\rho\left(\mathrm{kgm}^{-3}\right)$ is the fluid density, $v_{1}$ and $v_{2}\left(\mathrm{~ms}^{-1}\right)$ are the fluid speed upstream and through the nozzle, respectively, $h_{1}$ and $h_{2}(\mathrm{~m})$ are the heights of the fluid, and $g$ (ms2 ) is gravity. The third term at each side of Eq. (1) represents the specific potential energy, while the second term represents the specific kinetic energy. Assuming equal heights, the pressure drop $\left(P_{2}<P_{1}\right)$ at the reactor's nozzle arises because of the fluid acceleration due to mass conservation $\left(v_{2}>v_{1}\right)$. Whenever $P_{2}$ drops below the vapor pressure, at a certain temperature level, local evaporation occurs, and vapor bubbles are generated.

The dynamics of cavitation bubbles is quite complex. In a recent comprehensive article on HC dynamics, the Rayleigh-Plesset equation of bubble dynamics, representing the radial motion of the cavitation bubble, is only one in a set of four basic equations, the others representing the diffusive flux of water vapor molecules, the heat conduction across bubble wall, and the overall energy balance (Pawar et al., 2017). However, a widely used dimensionless quantity, named cavitation number $(\sigma)$ and derived from the Bernoulli's equation, can be used to characterize the cavitation intensity in a flow system, in terms of easily measurable physical quantities. Its representativeness holds in most of relatively simple HC reactors, such as Venturi tubes and orifice plates (Pawar et al., 2017), and relate it with the cavitational intensity, with cavitation generally arising for $\sigma<1$. The cavitation number is represented in Eq. (2):

$\sigma=\left(P_{0}-P_{v}\right) /\left(0.5 \cdot \rho \cdot v_{2}^{2}\right)$

where $P_{v}\left(\mathrm{Nm}^{-2}\right)$ is the liquid vapor pressure (a function of the average temperature for any given liquid), and the other symbols have the same meaning as in Eq. (1). Apparently, $\sigma$ represents the ratio between the pressure drop needed to achieve vaporization, and the specific kinetic energy at the cavitation inception section. Despite some recent, motivated criticism (Šarc, Stepišnik-Perdih, Petkovšek, \& Dular, 2017), $\sigma$ allows representing the features of HC processes with confidence for most of practical purposes (Soyama \& Hoshino, 2016), provided that the relevant quantities are measured properly.

Briefly, three intervals in the range of values assumed by the cavitation number were identified, corresponding to distinct HC regimes (Bagal \& Gogate, 2014; Gogate, 2002):

- $0<\sigma<0.1$ - cavitation can be chocked, with an almost stationary bubble cloud arising from the merging of individual bubbles, and no, or very weak and rare, collapsing events, in a regime called supercavitation.

- $0.1<\sigma<1$ - cavitation is developed, with fairly strong and frequent collapses.

- $\sigma>1$ - cavitation becomes residual, depending on the nature and concentration of impurities and dissolved gases, and virtually absent for $\sigma>4$, with rare but very strong collapses. 
However, cavitation regimes are subtly modulated by several details, such as the reactor's geometry (Carpenter, Badve, et al., 2017; Šarc et al., 2017), the flow rate and the inlet pressure, the geometry and the mechanical power of the impellers (Carpenter, Badve, et al., 2017; Pawar et al., 2017), as well as the content in dissolved gases and solid particles (Patil \& Pandit, 2007). The medium temperature also plays an important role, with a peak in cavitation aggressiveness around $60^{\circ} \mathrm{C}$ (Dular, 2016; Li, Yang, Shi, Zhao, \& Li, 2018).

Cavitation processes concentrate the energy of the bulk liquid medium, up to extremely high local density, into a myriad of microscopic hot spots, located at the collapse of the bubbles (Pawar et al., 2017; Yasui et al., 2004). As a result, extreme physical phenomena arise, such as temperature and pressure transients up to 5,000-10,000 $\mathrm{K}$ and $>300 \mathrm{~atm}$, respectively, very strong shear forces, micro-jets and pressure shockwaves. Powerful oxidants form, such as hydroxyl radicals $(\cdot \mathrm{OH}$, oxidation potential $2.80 \mathrm{eV})$, as a result of water splitting (Yasui et al., 2004), whose generation was explained by a set of reactions based on theoretical and experimental arguments (Carpenter, Badve, et al., 2017; Ciriminna et al., 2017; Sarvothaman et al., 2018).

While oxidation processes are needed for the degradation of organic contaminants, they are harmful for the quality of processed food liquids (Ngadi, Latheef, \& Kassama, 2012). However, within the range of HC regimes used in food applications, and absent any specific oxidizing additives, such processes are too mild to represent a real threat (Yusaf \& Al-Juboori, 2014). Actually, no oxidation whatsoever was observed either in wort or in final beer produced by means of $\mathrm{HC}$-assisted brewing processes (Albanese, Ciriminna, Meneguzzo, \& Pagliaro, 2017).

As extensively discussed in a recent review study (Albanese \& Meneguzzo, 2019a), among fixed HC reactors, Venturi tubes were preferred over orifice plates in the treatment of viscous food liquids. This superiority holds especially with liquids containing solid particles, as well as for the inactivation of spoilage microorganisms (Albanese et al., 2015), and for the creation of oil-in-water stable nanoemulsions (Carpenter, George, \& Saharan, 2017).

However, a virtually endless variety of Venturi reactors exists, leading to different results in terms of process yields. At the respective optimized geometries, as a rule, slit Venturi reactors outperform circular Venturi in terms of process yields. This holds, for example, for the removal of total organic content from recalcitrant pollutants in wastewater, and for the creation of stable oil-in-water nanoemulsions; as well, wide margins exist for further improving the performances, including the effect of the slit length as a function of its height (Barik \& Gogate, 2017; Carpenter, Badve, et al., 2017; Ramisetty, Pandit, \& Gogate, 2014).

\section{Hydrodynamic Cavitation and the Water-Energy-Food Nexus}

\subsection{Water and energy in the food production chain}

The food production chain revolves around water, with the main clean water fluxes involved in food growth (farming), cleaning and processing, and wastewater streams deriving from the water discharge after any of the above-mentioned uses, with wastewater, desirably, not simply discharged as sewage, but recovered for further use. 
Energy supply, in turn, powers cleaning and remediating systems for input water and wastewater streams, as well as food-processing devices, the latter comprising essential steps, such as those aimed at grinding and homogeneization, ensuring microbiological and physical stability, and food storage. Substantial amounts of energy, as well as other resources such as soil improvers and fertilizers, and pesticides, are also required to grow food.

The food itself supplies energy to humans, along with macronutrients and micronutrients. Vitamins and other micronutrients, such as certain phytochemicals available in plant-based food, modulate the effectiveness of the physiological use of food energy, and are essential for health and well-being (Bayram et al., 2018; Willett et al., 2019). Thus, food-manufacturing processes are desirable, which combine the capabilities of producing safe, health-effective, and durable products, while achieving high process yields (i.e., actual net production of desired products per unit energy supplied to the process) with regard to target properties of the products. Based on the desirable spreading of plant-based food in the human diet, as highlighted in Section 1, processes able to enhance the nutritional and nutraceutical value of products derived from vegetable materials, including unconventional sources, such as waste and byproducts of the food and biomass processing chains, would be extremely desirable too.

\subsection{Energy-saving HC applications in the food production chain}

Basically, HC's outperformance over conventional techniques lies in the fact that physico-chemical and biological reactions and processes can be carried out faster and more efficiently at ambient conditions, and at a lower cost, due to the intense energy delivery at the molecular level in the course of bubbles collapse (Carpenter, Badve, et al., 2017). Consequently, HC processing times were found generally shorter than in conventional extraction techniques, due to the maximization of the mass transfer coefficient generated by cavitation, translating into lower energy consumption (Cravotto et al., 2018).

In applications requiring working temperatures above the room level, such as in water disinfection and food pasteurization and sterilization, the heating efficiency can affect remarkably the process yields. $\mathrm{HC}$ processes showed excellent heating efficiency with a rotor-stator setup of the reactor (Sun et al., 2018). As well, all else being equal, the thermal efficiency was surprisingly higher when a closed loop pumping system comprised a Venturi-shaped HC reactor (Bermejo, Escaler, \& Dular, 2018). It should also be noted that electricity is the only power source for HC processes, and it is increasingly generated worldwide by means of renewable energy sources; thus, spreading the adoption of $\mathrm{HC}$ techniques would contribute to a substantial improvement of the exergetic sustainability of the food production chain (Zisopoulos, Rossier-Miranda, van der Goot, \& Boom, 2017).

A recent, comprehensive and authoritative review explored the main fields where HC can be applied, as a process intensification technique, with distinct advantages over competing techniques (Holkar, Jadhav, Pinjari, \& Pandit, 2019). Such processes include water disinfection, wastewater treatment, emulsification, crystallization, synthesis of nanomaterials, delignification, depolymerization, and extraction from biological materials, resulting in higher energy efficiency and process yield, higher efficacy, reduced 
resource use (solvents, surfactants, oxidizing reagents, etc.), lesser or no toxic byproducts, and, sometimes, higher quality products. Moreover, in the same study, HC's superiority over other cavitation techniques, such as the acoustic and optic ones, was firmly asserted, in terms of efficacy beyond the laboratory scale, energy efficiency, and scalability, although this topic was substantially decided long ago (Gogate \& Pandit, 2005; Gogate et al., 2001; Save, Pandit, \& Joshi, 1997).

In another recent review, the process yield metric was standardized, aimed at the objective comparison of the energy efficiency of different processes and competing technologies resulting in the same products (Albanese \& Meneguzzo, 2019a). Yields resulting from $\mathrm{HC}$-assisted processes always exceeded the corresponding figures associated to any other technology, either conventional or newer, with acoustic cavitation (AC) lagging behind by a factor greater than three. In particular, conventional heat treatment, typical of food pasteurization processes, while outperforming some of the newer techniques, such as high pressure or pulsed electric field, lagged behind HC by a factor of at least 1.2. However, in the case of complex processes, implemented in a single unit operation HC-based system, such as for beer-brewing (Albanese et al., 2017), with pasteurization being only one among many different process steps, the outperformance rose to a factor of around 2.5, or even higher under particular brewing conditions (Albanese, Ciriminna, Meneguzzo, \& Pagliaro, 2018).

Lately, higher process yields achieved by means of $\mathrm{HC}$ processes were shown for different applications. In the enhancement of biochar properties, HC processes achieved process yields 7 to 30 times higher in comparison with conventional slow thermal pyrolysis (Albanese, Baronti, et al., 2019). In the food production field, the HC-driven lethality effect for yeasts, and heat-resistant molds, was shown to be higher by at least an order of magnitude in comparison with high-pressure homogenization, and two orders of magnitude in comparison with AC (Fan, Martynenko, Doucette, Hughes, \& Fillmore, 2018).

\subsection{Water-saving HC applications in the food production chain}

HC processes can contribute to save and preserve freshwater resources in different stages of the food production chain. A recent study investigated the effects of irrigation with tap water enriched with air micro- and nano-bubbles, generated by means of a Venturi tube HC reactor provided with an air inlet valve, on some morphological and physiological properties of cucumbers grown in greenhouse (Dahrazma, Naghedinia, Ghasemian Gorji, \& Saghravani, 2019). Stem length, leaves number, blossom number, chlorophyll a, chlorophyll b, and carotenoids, increased by 1.14, 2.86, 3.80, 1.34, 1.44 and 1.35 times, respectively, in the plants after 12 weeks. The higher crop yield, and the enhanced functional properties, could help saving farming cost, land consumption, and irrigation water.

Irrigation water can be saved for crops growing in soils showing higher water-retaining properties. Biochar manufactured with the assistance of HC processes showed enhanced physical properties, likely leading to increased water retention when deployed in the soil (Albanese, Baronti, et al., 2019).

HC processes were shown able to extract more phytochemicals, such as polyphenols and flavonoids, and achieve remarkably higher antioxidant activity, in comparison with 
conventional extraction techniques, without the use of any synthetic solvent, i.e., with water as the only solvent. Case studies included cereals and fruits (Lohani, Muthukumarappan, \& Meletharayil, 2016), as well as other vegetable and plant materials, such as fir needles (Albanese, Bonetti, D’Acqui, Meneguzzo, \& Zabini, 2019). Solventfree extraction allowed not only the extraction of healthier and safer products, but also a reduction of waste byproducts and wastewater, thus, in principle, the reuse of processing water, or even the direct use of the resulting aqueous solutions for human consumption. Many studies demonstrated the higher comparative efficacy and efficiency of HC processes in the mineralization, degradation, and reduction, of the total organic content and the chemical oxygen demand of wastewaters containing organic pollutants. The respective performance increased with the use of suitable oxidizing additives, such as hydrogen peroxide, in remarkably lower doses in comparison with conventional techniques, as well avoiding the generation of hazardous byproducts (Ciriminna et al., 2017). The removal of persistent and recalcitrant pesticides was especially interesting for applications to farming-generated wastewater (Panda \& Manickam, 2019b).

Finally, HC processes have shown unrivaled ability in the real-scale disinfection of water from spoilage and harmful microorganisms, with a curious double peak of efficacy, one in the developed cavitation regime at relatively high levels of the cavitation number (Albanese et al., 2015; Carpenter, Badve, et al., 2017), the other in the supercavitation regime (Šarc, Kosel, Stopar, Oder, \& Dular, 2018). As well, laboratory-scale HC processes were shown able to inactivate even some viruses (Kosel et al., 2017). Combined capabilities to effectively and efficiently remediate and disinfect wastewater, in principle could allow their reuse for further irrigation, leading to the saving of freshwater resources.

\subsection{HC-driven exploitation of plant-based food}

As shortly discussed in Section 1, the shift to a plant-based diet is likely to be the single most important step to alleviate the burden of the food production chain on the terrestrial ecosystems and the climate. As well, it is likely to lead to comparable or even greater benefits to the general health, alleviating the related economic burden.

Evidence has accumulated about significant inverse correlations between plant antioxidants intake and the risk for cardiovascular diseases, type 2 diabetes, hypercholesterolemia, some cancers, and other globally spreading chronic diseases (Albanese et al., 2018; Tang et al., 2017), as well as no recommended upper limits apply to the intake of antioxidants, for the purpose of health benefits. Indeed, a monotonic increase of the ratio of the antioxidant activity (AA) to the oxidant status in the human blood serum (serum antioxidant/oxidant balance), with the long-term intake of antioxidant bioactive compounds, was recently found, and related to a sort of homeostatic equilibrium (Laus et al., 2017; Soccio, Laus, Alfarano, et al., 2018).

Lately, by means of a novel AA assay, more representative of the real human physiology, a very effective synergism was demonstrated among mixtures of food-grade extracts, as well as among hydrophilic, lipophilic and insoluble-bound phenolic extracts (Soccio, Laus, Flagella, et al., 2018). Such synergism was up to two orders of magnitude greater than revealed by means of classical in vitro assays. This result supported the long-known evidence about the higher effectivity of mixtures of plant phytochemicals (including 
phenolics, carotenoids, vitamin E, lignans, $\beta$-glucan, inulin, resistant starch, sterols, and phytates), for the prevention of cancer, cardiovascular disease, type 2 diabetes, and allcause mortality, in comparison to single phytochemicals (Rui Hai Liu, 2004, 2007). So much, that it was recommended long since to acquire antioxidants or bioactive compounds through whole-food consumption, rather than from expensive dietary supplements (R. H. Liu, 2013).

Therefore, processing of plant foods, including vegetable beverages, should at least avoid damaging the bioactive phytochemicals, for example due to thermal degradation (Domínguez Avila, Wall Medrano, Ruiz Pardo, Montalvo González, \& González Aguilar, 2017), while preserving their variety and abundance, including bound phenolics. Whole beverages, possibly including multiple functional ingredients, have the potential to convey superior health benefits than extracts, supplements, and single-ingredient beverages, provided that bioactive compounds are effectively extracted in the liquid phase, as well as go mostly undamaged in the processing. Moreover, processing costs should be kept as low as possible, translating into affordability for end users, as well as the sensorial properties of the products should be as attractive to the general public as possible.

HC processes can lead to enhanced extraction of bioactive compounds in the aqueous phase (i.e., in the end product), by means of the increased release of the respective fraction bound in carbohydrates, lignin, pectin, and proteins, due to the increase of the mass transfer rate and the interphase area (Cravotto et al., 2018; Panda \& Manickam, 2019a). Combined with the reduced degradation of the bioactive compounds, due to lower working temperatures (Martynenko \& Chen, 2016), higher AA levels could be achieved (Albanese \& Meneguzzo, 2019a).

In the case of blueberry (Fan et al., 2018; Martynenko, Astatkie, \& Satanina, 2015; Martynenko \& Chen, 2016), and cranberry (Chen \& Martynenko, 2017), the HC-based enhanced extraction of bioactive compounds (especially anthocyanins) from the whole fruits, combined with superior shelf life achieved at moderate temperatures, allowed straightforward industrialization ("Healthy Berries Ltd - Superfruit Purée," 2019). With sorghum flour and apple pomace, the HC treatment led to AA increasing by $38.6 \%$ and 97\%, respectively (Lohani et al., 2016).

In the $\mathrm{HC}$-assisted brewing process, increased extraction of polyphenols, and higher AA, was shown with raw unmalted grains (Albanese et al., 2018), as well as boosted extraction of prenylflavonoids from pelletized hops (Ciriminna et al., 2018), both leading to improved healthy properties and shelf life of the end product. Along with higher process yields (Albanese \& Meneguzzo, 2019b), these distinctive advantages allowed the development of the HC-based brewing system up to the industrial level (CAVIBEER | CNR \& Bysea S.r.l., 2018).

High content of polyphenols and flavonoids, and surprisingly high AA, were revealed in aqueous solutions obtained by means of real-scale, HC-driven solvent-free extraction of silver fir (Abies Alba Mill) needles in a concentration as low as $0.44 \% \mathrm{w} / \mathrm{v}$ (Albanese, Bonetti, et al., 2019). In particular, the in vitro AA at the level of $10 \mu \mathrm{g} / \mathrm{ml}\left(\mathrm{IC}_{50}, \mathrm{DPPH}\right.$ assay) was higher than shown by most reference substances, as well as by vitamins $C$ and E.

The transition to plant-based diets could be facilitated by the full exploitation of 
nutrients, mainly proteins, which are generally available in lower concentration than in animal-based food. Reduction of particle size and effective cell disruption were the basic steps allowing a HC-based high pressure homogenization treatment to increase the protein availability from soybean processing materials, especially slurry, with the protein extraction yield increased by $82 \%$ (Preece, Hooshyar, Krijgsman, Fryer, \& Zuidam, 2017). The HC treatment was found to outperform the AC one, as well as showed straightforward scalability. HC-based manufacturing of soymilk is already an industrial reality ("Food industry - TECNIDOS Sistemas y Procesos," 2019).

$\mathrm{HC}$ processes found convenient application also with unconventional, land-neutral plant materials, such as microalgae. High HC-driven extraction yield of lipids (25.9-99\%) from microalgae (Nannochloropsis salina) was obtained, due to the effective cell disruption, showing decreased energy consumption and straightforward scalability (Lee \& Han, 2015), as well as it emerged as the fastest process of lipid extraction in comparison to conventional methods (Setyawan, Mulyono, \& Budiman, 2018). HC-based edible oil (including algae's oil) extraction and refining technologies have already reached the industrial level ("Degumming | Arisdyne," 2019; "Edible oil refining | Cavitation Technologies, Inc.," 2019).

\subsection{Advantageous HC applications in the food production chain}

HC technologies, and the related methods, can help addressing any of the steps related to the food production chain, from farming to storage. A scheme highlighting the possible contributions of HC processes is shown in Fig. 2, with details provided in Table 1. It should be noted that biochar, which can be conveniently manufactured with the assistance of HC processes (Albanese, Baronti, et al., 2019), can in turn be applied to both soil amendment and water retention, and wastewater remediation. Moreover, the food processing step can be assisted by HC processes if the food material can be pumped along a hydraulic circuit, i.e., if it consists of a liquid or mixed solid-liquid matrix, such as, for example, beer wort containing water, grains, and hops (Albanese et al., 2017).

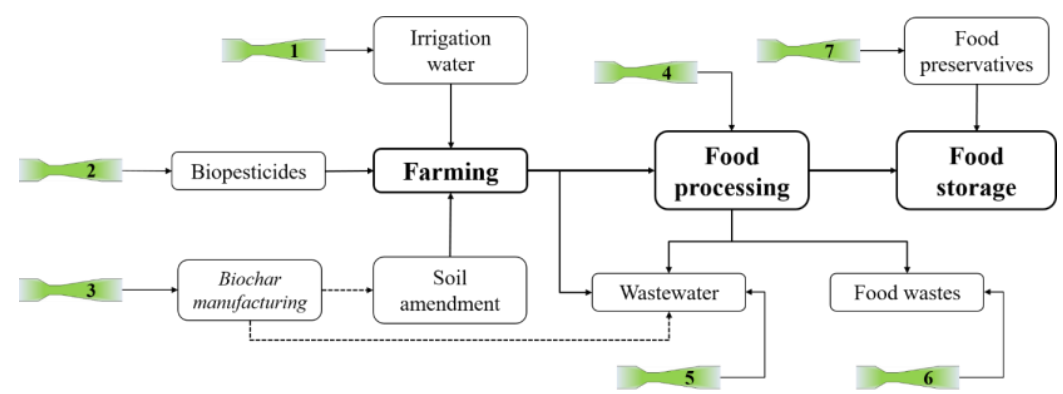

Figure 2. Partial scheme of the possible contributions of hydrodynamic cavitation processes to conventional food production chains. Numbers refer to HC processes applicable to different steps of the food production chains. 
Table 1. Possible contributions of hydrodynamic cavitation processes to conventional food production chains: details.

\begin{tabular}{|c|c|c|c|c|c|}
\hline Step ${ }^{a}$ & Main applications & $\begin{array}{l}\text { HC } \\
\text { setup / regime }\end{array}$ & Main relative advantages ${ }^{c}$ & TRL & References $^{\mathrm{e}}$ \\
\hline \multirow[b]{2}{*}{1} & $\begin{array}{l}\text { Desalination of sea and } \\
\text { brackish water }\end{array}$ & $\begin{array}{l}\text { Rotor-stator / } \\
\text { supercavitation }\end{array}$ & $\begin{array}{l}\text { Absence of scaling / fouling; } \\
\text { higher energy and economical } \\
\text { efficiency }\end{array}$ & 3 & $\begin{array}{l}\text { (Zheng et al., } \\
\text { 2019) }\end{array}$ \\
\hline & $\begin{array}{l}\text { Oxygen-enriched irrigation } \\
\text { water }\end{array}$ & $\begin{array}{l}\text { Venturi / } \\
\text { developed } \\
\text { cavitation }\end{array}$ & $\begin{array}{l}\text { Increase in plant growth and } \\
\text { enhancement of physiological } \\
\text { indices }\end{array}$ & 6 & $\begin{array}{l}\text { (Dahrazma et } \\
\text { al., 2019) }\end{array}$ \\
\hline 2 & $\begin{array}{l}\text { Stable nanoemulsions of } \\
\text { essential oils as biopesticides }\end{array}$ & $\begin{array}{l}\text { Venturi / } \\
\text { developed } \\
\text { cavitation }\end{array}$ & $\begin{array}{l}\text { Less use of } \\
\text { emulsifiers/surfactants; more } \\
\text { effective action; controlled and } \\
\text { prolonged release }\end{array}$ & 3 & $\begin{array}{l}\text { (Albanese, } \\
\text { Bonetti, et al., } \\
\text { 2019) }\end{array}$ \\
\hline 3 & $\begin{array}{l}\text { Enhancement of biochar } \\
\text { properties for soil } \\
\text { amendment and water } \\
\text { retention }\end{array}$ & $\begin{array}{l}\text { Venturi / } \\
\text { developed } \\
\text { cavitation }\end{array}$ & $\begin{array}{l}\text { Enhanced physico-chemical } \\
\text { properties; higher energy } \\
\text { efficiency and process yield }\end{array}$ & 6 & $\begin{array}{l}\text { (Albanese, } \\
\text { Baronti, et al., } \\
\text { 2019) }\end{array}$ \\
\hline 4 & $\begin{array}{l}\text { Food liquids } \\
\text { homogenization, } \\
\text { pasteurization and } \\
\text { sterilization, emulsification, } \\
\text { extraction and reaction } \\
\text { intensification, single-unit } \\
\text { operation }\end{array}$ & $\begin{array}{l}\text { Any setup / } \\
\text { developed } \\
\text { cavitation }\end{array}$ & $\begin{array}{l}\text { Enhanced preservation of } \\
\text { thermolabile compounds; } \\
\text { enhanced physical and } \\
\text { microbiological stability; higher } \\
\text { energy efficiency and process } \\
\text { yield }\end{array}$ & $5-9$ & $\begin{array}{l}\text { (Albanese \& } \\
\text { Meneguzzo, } \\
\text { 2019b) }\end{array}$ \\
\hline \multirow{2}{*}{5} & $\begin{array}{l}\text { Removal/degradation of } \\
\text { organic and recalcitrant water } \\
\text { pollutants }\end{array}$ & $\begin{array}{l}\text { Any setup / } \\
\text { developed } \\
\text { cavitation }\end{array}$ & $\begin{array}{l}\text { Less use of oxidizing additives; } \\
\text { higher energy efficiency and } \\
\text { process yield }\end{array}$ & $5-9$ & $\begin{array}{l}\text { (Ciriminna et } \\
\text { al., 2017) }\end{array}$ \\
\hline & $\begin{array}{l}\text { Water disinfection from } \\
\text { bacteria and harmful } \\
\text { microorganisms }\end{array}$ & $\begin{array}{l}\text { Rotor-stator and } \\
\text { Venturi / } \\
\text { supercavitation }\end{array}$ & $\begin{array}{l}\text { Enhanced microbiological } \\
\text { stability; higher energy and } \\
\text { economic efficiency }\end{array}$ & 4 & $\begin{array}{l}\text { (Šarc et al., } \\
2018)\end{array}$ \\
\hline 6 & $\begin{array}{l}\text { Extraction of valuable } \\
\text { bioactive compounds, } \\
\text { solubilization }\end{array}$ & $\begin{array}{l}\text { Any setup / } \\
\text { developed } \\
\text { cavitation }\end{array}$ & $\begin{array}{l}\text { Economic valorization of food } \\
\text { wastes; more efficient use of } \\
\text { residues to feed livestock or } \\
\text { biogas generation plants }\end{array}$ & 9 & $\begin{array}{l}\text { (Grillo et al., } \\
\text { 2019) }\end{array}$ \\
\hline 7 & $\begin{array}{l}\text { Extraction of antioxidant and } \\
\text { antimicrobial compounds } \\
\text { affecting shelf-life }\end{array}$ & $\begin{array}{l}\text { Venturi / } \\
\text { developed } \\
\text { cavitation }\end{array}$ & $\begin{array}{l}\text { Enhanced extraction rate; } \\
\text { higher energy efficiency and } \\
\text { process yield }\end{array}$ & 8 & $\begin{array}{l}\text { (Ciriminna et } \\
\text { al., 2018) }\end{array}$ \\
\hline
\end{tabular}

${ }^{\text {a Numbers in this column refer to Fig. } 2 .}$

b Relative to the cited reference.

c In comparison with competing technologies.

d Technology readiness level (Mankins, 2009).

e Only the most representative or recent reference is supplied for each of the considered applications.

f This reference recommends the relevant application for further research.

\section{Discussion and Conclusions}

At the current stage of development, hydrodynamic cavitation technologies are ready to favor a substantial efficiency leap in virtually any step of the food production chain, due to their applicability to many different processes, either stand-alone or in synergy with conventional techniques, the ability to intensify physico-chemical reactions and processes, the superior process yields, and the straightforward scalability. However, the lack of adequate standardization for any given application, affecting both the proper choice among different classes of HC reactors, and, within a specific class of reactors, 
the choice of the suitable process parameters, are still partially hindering the widespread adoption.

Nevertheless, industrial-level applications are emerging and fulfilling promises, while scholars are increasingly active in the search for new applications, and the definition of case-specific structural and process parameters. This review provided a short but hopefully representative view of the current trends.

About future perspectives, it should be noted that $\mathrm{HC}$ techniques can be applied to the processing of virtually any food material that has been the subject of experiments by means of AC techniques, provided that such material can be pumped along a piping system. Since AC has been experimented much more frequently, and with far more substances, than HC, including in food processing and extraction applications, although mostly at the laboratory scale, a virtually endless field of new applications for $\mathrm{HC}$ processes exists, with proven advantages, such as straightforward scalability and much higher process yields, likely to extend to any new case study.

As a representative example, $\mathrm{AC}$-assisted extraction of polyphenols from maritime pine sawdust, a by-product from the industry of wood transformation, thus non-competitive with either food crops and land use, outperformed conventional maceration by $40 \%$ at the laboratory scale, such figure decreasing with scaling-up (Meullemiestre, Petitcolas, Maache-Rezzoug, Chemat, \& Rezzoug, 2016). The opposite trend is expected for a possible HC application to the same process, which is thus recommended for further research.

Sometimes, industry seems to have taken advantage of research, to turn laboratory-scale AC applications into real-scale marketable HC systems. This is the case of the extraction of bioactive compounds from Cannabis Sativa L., such as polyphenols, flavonoids, and cannabinoids, which was shown to increase at least by $100 \%$ under AC conditions, in comparison with the control extraction (Agarwal, Máthé, Hofmann, \& Csóka, 2018). In 2018, a company introduced in the market an HC-based extraction system, claimed to treat the whole plant, converting cannabinoids into nanoemulsions, and, combined with moderate working temperatures, ensuring higher bioavailability, in additions to using much less solvents, and cutting production costs ("PhytoX | Hydrodynamic Extraction | Full Spectrum Extraction Cannabis," 2018).

Both phytochemicals whose dietary intake is potentially beneficial to human health, and plants candidate for the respective extraction, are countless, with the in vivo effects still to be determined in most of the cases, let alone the possible synergisms and the methods of use, such as for the fortification of functional and medicinal beverages (Eksi, Kurbanoglu, \& Ozkan, 2019). Either AC or HC have not yet been applied to the vast majority of plant materials and the extraction of the respective phytochemicals. This evidence, combined with quickly rising market trends for plant-based, healthy beverages, as well as for greener pesticides, offer research and applications concerning HC techniques and methods, with their proven competitive advantages, a bright future ahead. 


\section{References}

Agarwal, C., Máthé, K., Hofmann, T., \& Csóka, L. (2018). Ultrasound-Assisted Extraction of Cannabinoids from Cannabis Sativa L. Optimized by Response Surface Methodology. Journal of Food Science, 83(3), 700-710. https://doi.org/10.1111/1750-3841.14075

Albanese, L., Baronti, S., Liguori, F., Meneguzzo, F., Barbaro, P., \& Vaccari, F. P. (2019). Hydrodynamic cavitation as an energy efficient process to increase biochar surface area and porosity: A case study. Journal of Cleaner Production, 210, 159-169. https://doi.org/10.1016/J.JCLEPRO.2018.10.341

Albanese, L., Bonetti, A., D’Acqui, L. P., Meneguzzo, F., \& Zabini, F. (2019). Affordable Production of Antioxidant Aqueous Solutions by Hydrodynamic Cavitation Processing of Silver Fir (Abies Alba Mill.) Needles. Foods, 8(2), 65. https://doi.org/10.3390/foods8020065

Albanese, L., Ciriminna, R., Meneguzzo, F., \& Pagliaro, M. (2015). Energy efficient inactivation of Saccharomyces cerevisiae via controlled hydrodynamic cavitation. Energy Science \& Engineering, 3(3), 221-238. https://doi.org/10.1002/ese3.62

Albanese, L., Ciriminna, R., Meneguzzo, F., \& Pagliaro, M. (2017). Beer-brewing powered by controlled hydrodynamic cavitation: Theory and real-scale experiments. Journal of Cleaner Production, 142, 1457-1470. https://doi.org/10.1016/j.jclepro.2016.11.162

Albanese, L., Ciriminna, R., Meneguzzo, F., \& Pagliaro, M. (2018). Innovative beer-brewing of typical, old and healthy wheat varieties to boost their spreading. Journal of Cleaner Production, 171, 297-311. https://doi.org/10.1016/j.jclepro.2017.10.027

Albanese, L., \& Meneguzzo, F. (2019a). 10 - Hydrodynamic Cavitation Technologies: A Pathway to More Sustainable, Healthier Beverages, and Food Supply Chains. In A. M. Grumezescu \& A. M. Holban (Eds.), Processing and Sustainability of Beverages (pp. 319-372). https://doi.org/10.1016/B978-0-12815259-1.00010-0

Albanese, L., \& Meneguzzo, F. (2019b). 7 - Hydrodynamic Cavitation-Assisted Processing of Vegetable Beverages: Review and the Case of Beer-Brewing. In A. M. Grumezescu \& A. M. Holban (Eds.), Production and Management of Beverages (pp. 211-257). https://doi.org/10.1016/B978-0-12-8152607.00007-9

Bagal, M. V, \& Gogate, P. R. (2014). Wastewater treatment using hybrid treatment schemes based on cavitation and Fenton chemistry: a review. Ultrasonics Sonochemistry, 21(1), 1-14. https://doi.org/10.1016/j.ultsonch.2013.07.009

Bajželj, B., Richards, K. S., Allwood, J. M., Smith, P., Dennis, J. S., Curmi, E., \& Gilligan, C. A. (2014). Importance of food-demand management for climate mitigation. Nature Climate Change, 4(10), 924-929. https://doi.org/10.1038/nclimate2353

Barik, A. J., \& Gogate, P. R. (2017). Hybrid treatment strategies for 2,4,6-trichlorophenol degradation based on combination of hydrodynamic cavitation and AOPs. Ultrasonics Sonochemistry, 40, 383-394. https://doi.org/10.1016/j.ultsonch.2017.07.029

Bayram, B., González-Sarrías, A., Istas, G., Garcia-Aloy, M., Morand, C., Tuohy, K., ... Mena, P. (2018). Breakthroughs in the Health Effects of Plant Food Bioactives: A Perspective on Microbiomics, Nutri(epi)genomics, and Metabolomics. Journal of Agricultural and Food Chemistry, 66(41), 1068610692. https://doi.org/10.1021/acs.jafc.8b03385

Bermejo, D., Escaler, X., \& Dular, M. (2018). Experimental Investigation of the Cavitation Effects on the Heat Generation in a Closed Loop Pumping System. In J. Katz \& B. Adamson (Eds.), The 10th International Symposium on Cavitation (CAV2018). Retrieved from https://cav2018.jhu.edu/wpcontent/uploads/Escaler-Xavier.pdf

Carpenter, J., Badve, M., Rajoriya, S., George, S., Saharan, V. K., \& Pandit, A. B. (2017). Hydrodynamic cavitation: an emerging technology for the intensification of various chemical and physical processes in a chemical process industry. Reviews in Chemical Engineering, 33(5), 433-468. https://doi.org/10.1515/revce-2016-0032

Carpenter, J., George, S., \& Saharan, V. K. (2017). Low pressure hydrodynamic cavitating device for producing highly stable oil in water emulsion: Effect of geometry and cavitation number. Chemical Engineering and Processing: Process Intensification, 116, 97-104. https://doi.org/10.1016/j.cep.2017.02.013 
CAVIBEER | CNR \& Bysea S.r.l. (2018). Cavibeer. Retrieved January 9, 2019, from http://www.cavibeer.com/

Chen, Y., \& Martynenko, A. (2017). Storage stability of cranberry puree products processed with hydrothermodynamic (HTD) technology. LWT - Food Science and Technology, 79, 543-553. https://doi.org/10.1016/j.lwt.2016.10.060

Ciriminna, R., Albanese, L., Di Stefano, V., Delisi, R., Avellone, G., Meneguzzo, F., \& Pagliaro, M. (2018). Beer produced via hydrodynamic cavitation retains higher amounts of xanthohumol and other hops prenylflavonoids. LWT - Food Science and Technology, 91, 160-167. https://doi.org/10.1016/j.lwt.2018.01.037

Ciriminna, R., Albanese, L., Meneguzzo, F., \& Pagliaro, M. (2017). Wastewater remediation via controlled hydrocavitation. Environmental Reviews, 25(2), 175-183. https://doi.org/10.1139/er-2016-0064

Cravotto, G., Mariatti, F., Gunjevic, V., Secondo, M., Villa, M., Parolin, J., \& Cavaglià, G. (2018). Pilot Scale Cavitational Reactors and Other Enabling Technologies to Design the Industrial Recovery of Polyphenols from Agro-Food By-Products, a Technical and Economical Overview. Foods, 7(9), 130. https://doi.org/10.3390/foods7090130

Dahrazma, B., Naghedinia, A., Ghasemian Gorji, H., \& Saghravani, S. F. (2019). Morphological and Physiological Responses of Cucumis sativus L. to Water with Micro-Nanobubbles. Journal of Agricultural Science and Technology, 21(1), 181-192. Retrieved from http://jast.modares.ac.ir/article23-15964-en.html

Degumming | Arisdyne. (2019). Retrieved April 7, 2019, from http://www.arisdyne.com/content/degumming

Di Paola, A., Rulli, M. C., \& Santini, M. (2017). Human food vs. animal feed debate. A thorough analysis of environmental footprints. Land Use Policy, 67, 652-659. https://doi.org/10.1016/j.landusepol.2017.06.017

Dindar, E. (2016). An Overview of the Application of Hydrodinamic Cavitation for the Intensification of Wastewater Treatment Applications: A Review. Innovative Energy \& Research, 5(137), 1-7. https://doi.org/10.4172/ier.1000137

Doltade, S. B., Dastane, G. G., Jadhav, N. L., Pandit, A. B., Pinjari, D. V., Somkuwar, N., \& Paswan, R. (2019). Hydrodynamic cavitation as an imperative technology for the treatment of petroleum refinery effluent. Journal of Water Process Engineering, 29, 100768. https://doi.org/10.1016/j.jwpe.2019.02.008

Domínguez Avila, J. A., Wall Medrano, A., Ruiz Pardo, C. A., Montalvo González, E., \& González Aguilar, G. A. (2017). Use of nonthermal technologies in the production of functional beverages from vegetable ingredients to preserve heat-labile phytochemicals. Journal of Food Processing and Preservation, e13506. https://doi.org/10.1111/jfpp.13506

Dular, M. (2016). Hydrodynamic cavitation damage in water at elevated temperatures. Wear, 346, 78-86. https://doi.org/10.1016/j.wear.2015.11.007

Edible oil refining | Cavitation Technologies, Inc. (2019). Retrieved April 7, 2019, from http://www.ctinanotech.com/technology/edible-oil-refining

Eksi, G., Kurbanoglu, S., \& Ozkan, S. A. (2019). Fortification of Functional and Medicinal Beverages With Botanical Products and Their Analysis. In A. M. Grumezescu \& A. M. Holban (Eds.), Engineering Tools in the Beverage Industry (pp. 351-404). https://doi.org/10.1016/B978-0-12-815258-4.00012-3

Fan, L., Martynenko, A., Doucette, C., Hughes, T., \& Fillmore, S. (2018). Microbial Quality and Shelf Life of Blueberry Purée Developed Using Cavitation Technology. Journal of Food Science, 83(3), 732-739. https://doi.org/10.1111/1750-3841.14073

Food industry - TECNIDOS Sistemas y Procesos. (2019). Retrieved October 23, 2017, from http://www.tecnidos.com/en/index.php/nanocavitacion-hidrodinamica/industria-alimentaria/

Gogate, P. R. (2002). Cavitation: an auxiliary technique in wastewater treatment schemes. Advances in Environmental Research, 6(3), 335-358. https://doi.org/10.1016/S1093-0191(01)00067-3

Gogate, P. R., \& Pandit, A. B. (2001). Hydrodynamic cavitation reactors: a state of the art review. Reviews in Chemical Engineering, 17(1), 1-85. https://doi.org/10.1515/REVCE.2001.17.1.1

Gogate, P. R., \& Pandit, A. B. (2005). A review and assessment of hydrodynamic cavitation as a technology for the future. Ultrasonics Sonochemistry, 12(1-2 SPEC. ISS.), 21-27. https://doi.org/10.1016/j.ultsonch.2004.03.007 
Gogate, P. R., Shirgaonkar, I. Z., Sivakumar, M., Senthilkumar, P., Vichare, N. P., \& Pandit, A. B. (2001). Cavitation reactors: Efficiency assessment using a model reaction. AIChE Journal, 47(11), 25262538. https://doi.org/10.1002/aic.690471115

Grillo, G., Boffa, L., Binello, A., Mantegna, S., Cravotto, G., Chemat, F., .. Telysheva, G. (2019). Cocoa bean shell waste valorisation; extraction from lab to pilot-scale cavitational reactors. Food Research International, 115, 200-208. https://doi.org/10.1016/j.foodres.2018.08.057

Healthy Berries Ltd - Superfruit Purée. (2019). Retrieved April 7, 2019, from https://lovehealthyberries.ca/

Holkar, C. R., Jadhav, A. J., Pinjari, D. V., \& Pandit, A. B. (2019). Cavitationally Driven Transformations: A Technique of Process Intensification. Industrial \& Engineering Chemistry Research, acs.iecr.8b04524. https://doi.org/10.1021/acs.iecr.8b04524

Kosel, J., Gutiérrez-Aguirre, I., Rački, N., Dreo, T., Ravnikar, M., \& Dular, M. (2017). Efficient inactivation of MS-2 virus in water by hydrodynamic cavitation. Water Research, 124, 465-471. https://doi.org/10.1016/j.watres.2017.07.077

Laus, M. N., Soccio, M., Alfarano, M., Pasqualone, A., Lenucci, M. S., Di Miceli, G., \& Pastore, D. (2017). Different effectiveness of two pastas supplemented with either lipophilic or hydrophilic/phenolic antioxidants in affecting serum as evaluated by the novel Antioxidant/Oxidant Balance approach. Food Chemistry, 221, 278-288. https://doi.org/10.1016/j.foodchem.2016.10.050

Lee, I., \& Han, J. I. (2015). Simultaneous treatment (cell disruption and lipid extraction) of wet microalgae using hydrodynamic cavitation for enhancing the lipid yield. Bioresource Technology, 186, 246-251. https://doi.org/10.1016/j.biortech.2015.03.045

Li, W., Yang, Y., Shi, W. D., Zhao, X., \& Li, W. (2018). The correction and evaluation of cavitation model considering the thermodynamic effect. Mathematical Problems in Engineering, 2018(Article ID 7217513), 1-11. https://doi.org/10.1155/2018/7217513

Liu, R. H. (2004). Potential synergy of phytochemicals in cancer prevention: mechanism of action. The Journal of Nutrition, 134(12 Suppl), 3479S-3485S. https://doi.org/10.1093/jn/134.12.3479S

Liu, R. H. (2007). Whole grain phytochemicals and health. Journal of Cereal Science, 46(3), $207-219$. https://doi.org/10.1016/j.jcs.2007.06.010

Liu, R. H. (2013). Health-Promoting Components of Fruits and Vegetables in the Diet. Advances in Nutrition: An International Review Journal, 4(3), 384S-392S. https://doi.org/10.3945/an.112.003517

Lohani, U. C., Muthukumarappan, K., \& Meletharayil, G. H. (2016). Application of hydrodynamic cavitation to improve antioxidant activity in sorghum flour and apple pomace. Food and Bioproducts Processing, 100, 335-343. https://doi.org/10.1016/j.fbp.2016.08.005

Mankins, J. C. (2009). Technology readiness assessments: A retrospective. Acta Astronautica, 65(9-10), 12161223. https://doi.org/10.1016/j.actaastro.2009.03.058

Martynenko, A., Astatkie, T., \& Satanina, V. (2015). Novel hydrothermodynamic food processing technology. Journal of Food Engineering, 152, 8-16. https://doi.org/10.1016/j.jfoodeng.2014.11.016

Martynenko, A., \& Chen, Y. (2016). Degradation kinetics of total anthocyanins and formation of polymeric color in blueberry hydrothermodynamic (HTD) processing. Journal of Food Engineering, 171, 44-51. https://doi.org/10.1016/j.jfoodeng.2015.10.008

Meullemiestre, A., Petitcolas, E., Maache-Rezzoug, Z., Chemat, F., \& Rezzoug, S. A. (2016). Impact of ultrasound on solid-liquid extraction of phenolic compounds from maritime pine sawdust waste. Kinetics, optimization and large scale experiments. Ultrasonics Sonochemistry, 28, 230-239. https://doi.org/10.1016/J.ULTSONCH.2015.07.022

Motesharrei, S., Rivas, J., Kalnay, E., Asrar, G. R., Busalacchi, A. J., Cahalan, R. F., ... Zeng, N. (2017). Modeling sustainability: Population, inequality, consumption, and bidirectional coupling of the Earth and human Systems. National Science Review, 3(4), 470-494. https://doi.org/10.1093/nsr/nww081

Ngadi, M. O., Latheef, M. Bin, \& Kassama, L. (2012). Emerging technologies for microbial control in food processing. In J. I. Boye \& Y. Arcand (Eds.), Green technologies in food production and processing (pp. 363-411). https://doi.org/10.1007/978-1-4614-1587-9_14

Panda, D., \& Manickam, S. (2019a). Cavitation Technology-The Future of Greener Extraction Method: A Review on the Extraction of Natural Products and Process Intensification Mechanism and Perspectives. Applied Sciences, 9(4), 766. https://doi.org/10.3390/app9040766

Panda, D., \& Manickam, S. (2019b). Hydrodynamic cavitation assisted degradation of persistent endocrinedisrupting organochlorine pesticide Dicofol: Optimization of operating parameters and 
investigations on the mechanism of intensification. Ultrasonics Sonochemistry, 51, 526-532. https://doi.org/10.1016/j.ultsonch.2018.04.003

Patil, M. N., \& Pandit, A. B. (2007). Cavitation - A novel technique for making stable nano-suspensions. Ultrasonics Sonochemistry, 14(5), 519-530. https://doi.org/10.1016/j.ultsonch.2006.10.007

Pawar, S. K., Mahulkar, A. V., Pandit, A. B., Roy, K., \& Moholkar, V. S. (2017). Sonochemical effect induced by hydrodynamic cavitation: Comparison of venturi/orifice flow geometries. AIChE Journal, 63(10), 4705-4716. https://doi.org/10.1002/aic.15812

PhytoX | Hydrodynamic Extraction | Full Spectrum Extraction Cannabis. (2018). Retrieved April 7, 2019, from http://iasocorp.com/phytox/

Preece, K. E., Hooshyar, N., Krijgsman, A. J., Fryer, P. J., \& Zuidam, N. J. (2017). Intensification of protein extraction from soybean processing materials using hydrodynamic cavitation. Innovative Food Science and Emerging Technologies, 41, 47-55. https://doi.org/10.1016/j.ifset.2017.01.002

Ramisetty, K. A., Pandit, A. B., \& Gogate, P. R. (2014). Novel Approach of Producing Oil in Water Emulsion Using Hydrodynamic Cavitation Reactor. Industrial \& Engineering Chemistry Research, 53(42), 16508-16515. https://doi.org/10.1021/ie502753d

Rohmer, S. U. K., Gerdessen, J. C., \& Claassen, G. D. H. (2019). Sustainable supply chain design in the food system with dietary considerations: A multi-objective analysis. European Journal of Operational Research, 273(3), 1149-1164. https://doi.org/10.1016/j.ejor.2018.09.006

Šarc, A., Kosel, J., Stopar, D., Oder, M., \& Dular, M. (2018). Removal of bacteria Legionella pneumophila , Escherichia coli, and Bacillus subtilis by (super)cavitation. Ultrasonics Sonochemistry, 42, 228-236. https://doi.org/10.1016/j.ultsonch.2017.11.004

Šarc, A., Stepišnik-Perdih, T., Petkovšek, M., \& Dular, M. (2017). The issue of cavitation number value in studies of water treatment by hydrodynamic cavitation. Ultrasonics Sonochemistry, 34, 51-59. https://doi.org/10.1016/j.ultsonch.2016.05.020

Sarvothaman, V. P., Simpson, A. T., \& Ranade, V. V. (2018). Modelling of vortex based hydrodynamic cavitation reactors. Chemical Engineering Journal. https://doi.org/10.1016/j.cej.2018.08.025

Save, S. S., Pandit, A. B., \& Joshi, J. B. (1997). Use of Hydrodynamic cavitation for large scale microbial cell disruption. Trans IChemE, 75(C), 41-49. https://doi.org/DOI: 10.1205/096030897531351

Setyawan, M., Mulyono, P., \& Budiman, A. (2018). Comparison of Nannochloropsis sp . cells distuption between hydrodynamic cavitation and conventional extraction. MATEC Web of Conferences ICET4SD 2017, 154, 01023. https://doi.org/10.1051/matecconf/201815401023

Soccio, M., Laus, M., Flagella, Z., Pastore, D., Soccio, M., Laus, M. N., ... Pastore, D. (2018). Assessment of Antioxidant Capacity and Putative Healthy Effects of Natural Plant Products Using Soybean Lipoxygenase-Based Methods. An Overview. Molecules, 23(12), 3244. https://doi.org/10.3390/molecules23123244

Soccio, M., Laus, M. N., Alfarano, M., Dalfino, G., Panunzio, M. F., \& Pastore, D. (2018). Antioxidant/Oxidant Balance as a novel approach to evaluate the effect on serum of long-term intake of plant antioxidant-rich foods. Journal of Functional Foods, 40, 778-784. https://doi.org/10.1016/j.jff.2017.12.012

Soyama, H., \& Hoshino, J. (2016). Enhancing the aggressive intensity of hydrodynamic cavitation through a Venturi tube by increasing the pressure in the region where the bubbles collapse. AIP Advances, 6 , 045113. https://doi.org/10.1063/1.4947572

Springmann, M., Clark, M., Mason-D’Croz, D., Wiebe, K., Bodirsky, B. L., Lassaletta, L., ... Willett, W. (2018). Options for keeping the food system within environmental limits. Nature, 562(7728), 519 525. https://doi.org/10.1038/s41586-018-0594-0

Springmann, M., Godfray, H. C. J., Rayner, M., \& Scarborough, P. (2016). Analysis and valuation of the health and climate change cobenefits of dietary change. Proceedings of the National Academy of Sciences, 113(15), 4146-4151. https://doi.org/10.1073/pnas.1523119113

Sun, X., Park, J. J., Kim, H. S., Lee, S. H., Seong, S. J., Om, A. S., \& Yoon, J. Y. (2018). Experimental investigation of the thermal and disinfection performances of a novel hydrodynamic cavitation reactor. Ultrasonics Sonochemistry, 49, 13-23. https://doi.org/10.1016/j.ultsonch.2018.02.039

Tang, G. Y., Meng, X., Li, Y., Zhao, C. N., Liu, Q., \& Li, H. Bin. (2017). Effects of vegetables on cardiovascular diseases and related mechanisms. Nutrients, 9(8), 857. https://doi.org/10.3390/nu9080857 
Taylor, T. G., \& Tainter, J. A. (2016). The Nexus of Population, Energy, Innovation, and Complexity. American Journal of Economics and Sociology, 75(4), 1005-1043. https://doi.org/10.1111/ajes.12162

Tilman, D., \& Clark, M. (2014). Global diets link environmental sustainability and human health. Nature, 515(7528), 518-522. https://doi.org/10.1038/nature13959

Willett, W., Rockström, J., Loken, B., Springmann, M., Lang, T., Vermeulen, S., ... Murray, C. J. L. (2019). Food in the Anthropocene: the EAT-Lancet Commission on healthy diets from sustainable food systems. Lancet (London, England), 393(10170), 447-492. https://doi.org/10.1016/S01406736(18)31788-4

Yasui, K., Tuziuti, T., Sivakumar, M., \& Iida, Y. (2004). Sonoluminescence. Applied Spectroscopy Reviews, 39(3), 399-436. https://doi.org/10.1081/ASR-200030202

Yusaf, T., \& Al-Juboori, R. a. (2014). Alternative methods of microorganism disruption for agricultural applications. Applied Energy, 114, 909-923. https://doi.org/10.1016/j.apenergy.2013.08.085

Zheng, Z., Li, Q., Wang, L., Yao, L., Cai, W., Li, H., \& Li, F. (2019). Numerical study on morphological characteristics of rotational natural supercavitation by rotational supercavitating evaporator with optimized blade shape. Journal of Hydrodynamics, 1-17. https://doi.org/10.1007/s42241-019-0007-3

Zisopoulos, F. K., Rossier-Miranda, F. J., van der Goot, A. J., \& Boom, R. M. (2017). The use of exergetic indicators in the food industry - A review. Critical Reviews in Food Science and Nutrition, 57(1), 197211. https://doi.org/10.1080/10408398.2014.975335 